\title{
Perancangan Sistem Informasi Penjualan Barang Pada PT Asia Truk Pratama Jakarta
}

\author{
Isabel Ananda ${ }^{1}$, Eva Zuraidah ${ }^{2}$ \\ ${ }^{1}$ Sistem Informasi, Universitas Bina Sarana Informatika \\ isabelananda095@gmail.com \\ ${ }^{2}$ Sistem Informasi, STMIK Nusa Madiri \\ eva.evz@nusamandiri.ac.id
}

\begin{abstract}
Abstrak
PT Asia Truk Pratama merupakan sebuah usaha yang bergerak dibidang penjualan suku cadang atau spare part. Pada PT Asia Truk Pratama proses pencatatan dan pengelolahan data, jumlah, harga dan data transaksi penjualan masih dilakukan secara manual. Adapun tujuan dari penelitian ini adalah untuk merancang sistem informasi penjualan barang pada PT Asia Truk Pratama. Adapun metode-metode yang digunakan untuk menyelesaikan tugas akhir ini adalah metode pendekatan menggunakan sistem berorientasi objek sementara metode pengembangan sistem yang digunakan adalah Waterfall model. Sedangkan pemodelan sistemnya menggunakan metode Unifield Modeling Languange (UML) dengan menggunakan bahasa pemograman Java sedangkan Software/Tools yang digunakan adalan MySQL sebagai basis datanya. Sistem informasi penjualan barang ini dapat menjadi salah satu solusi yang dapat digunakan untuk mempermudah pemilik Perusahaan dalam mengelolah data penjualan ,laporan data serta pembuatan nota transaksi penjualan menjadi lebih mudah cepat dan efesien sehinggan dapat membantu meningkatkan keuntungan PT asia truk pratama dalam dalam menjalankan usahanya. Serta akan membantu mengambil keputusan yang akan membangun sistem informasi sehingga akan membantu membuat keputusan untuk meningkatkan pelayanan di PT Asia Truk Pratama.
\end{abstract}

Kata Kunci : Data Sparepart, UML, MySQL, Penjualan, Barang

\begin{abstract}
PT Asia Truk Pratama is a business engaged in the sale of spare parts or spare parts. At PT Asia Truk Pratama the process of recording and managing data, quantities, prices and sales transaction data is still done manually. The purpose of this study is to design an information system for selling goods at PT Asia Truk Pratama. The methods used to complete this final project are the approach method using object-oriented systems while the system development method used is the Waterfall model. While the system modeling uses the Unified Modeling Language (UML) method using the Java programming language while the Software / Tools used is MySQL as the database. This goods sales information system can be one solution that can be used to facilitate the owner of the company in managing sales data, data reports and making sales transaction notes easier and faster so they can help increase the profit of PT Asia Truk Pratama in running its business. And will help make decisions that will build an information system so that it will help make decisions to improve services at PT Asia Truk Pratama.
\end{abstract}

\section{Keywords: Data Spare Parts, UML, MySQL, Sales, Goods}

\section{Pendahuluan}

Pada PT Asia Truk Pratama belum ada proses pemesanan barang secara online sehingga menimbulkan banyak kendala yang dapat menggangu kelancaran dalam proses penjualan dan perdagangan.
Dengan demikian sistem tersebut membutuhkan pengembangan agar dapat mengurangi kesalahan-kesalahan dan juga dapat memberikan pelayanan yang lebih maksimal pada konsumen serta dapat memberikan kemudahan bagi PT Asia Truk 
Pratama, maka penulis merancang suatu aplikasi perancangan penjualan dan pemesanan Barang secara online pada PT Asia Truk Pratama

Menurut (Ika Nur Indah; 2015)

Suatu bidang usaha harus dapat mengenalkan diri dan barang yang mereka jualan sehingga konsumen yang belum tahu akan mengenalnya, yang sudah mengetahui akan semakin percaya sehingga akan mudah mendapatkan perhatian dari masyarakat. Bisnis merupakan suatu kegiatan usaha individu yang terorganisasi untuk menghasilkan dana menjual barang ataupun jasa agar mendapatkan keuntungan dalam pemenuhan kebutuhan masyarakat dan ada di dalam industri.

Menurut Munawar (2018) Metode yang digunakan pada pengembangan perangkat lunak ini menggunakan model waterfall yang terbagi menjadi tiga tahapan, yaitu:

1. Analisis Kebutuhan

2. Perancangan Sistem dan Perangkat Lunak

3. Implementasi dan Pengujian

Menurut Mulyani,(2016) Sistem adalah kumpulan dari dua atau lebih komponen yang saling bekerja dan berhubungan untuk mencapai tujuan tertentu. Dia juga berpenapat bahwa perusaahan adalah sebuah sistem yang terdiri dari beberapa departremen yang bertindak sebagai susbsitem yang membentuk sistem perusahaan tersebut. Sedangkan pendapat lain mengatakan sistem adalah suatu jaringan kerja dari proosedur-prosedur yang saling berhubungan, berkumpul bersamasama untuk melakukan suatu kegiatan atau untuk meyelesaikan suatu sasaran tertentu.

Menurut Batubara (2018) Web atau website adalah kumpulan dari halaman sistus dan dokumen yang tersebar dibeberapa komputer server yang berada di seluruh penjuru dunia dan terhubung menjadi satu jaringan yang disebut internet.

Menurut Hutahean (2015) Sistem adalah suatu jaringan kerja dari prosedurprosedur yang saling berhubungan, berkumpul bersama-sama untuk melakukan kegiatan atau untuk melakukan sasaran yang tertentu. Pendekatan sistem yang merupakan jaringan kerja dari prosedur lebih menekankan urutan-urutan operasi di dalam sistem.
Menurut Rusmawan (2019) Pemograman Berorientasi Objek (OOP) merupakan pradigma pemorgaman yang berointasikan kepada objek. Semua data dan fungsi di dalam pradigma ini dibungkus dalam kelas-kelas atau objek-objek.

Menurut Wahyuni(2018) Meliputi sebuah jaringan fisik dari serat optik, kabel tembaga ataupun peralatan lainnya yang mengubungkan sistem komputer yang memiliki perbedaan ukuran ataupun jumlah layanan dengan aturan-aturan teknins dan protokol yang memiliki tingkat ketepatan tinggi dalam eksekusinya pada jaringan fisik.

Menurut Marisa(2017) Website atau situs dapat diartikan sebagai kumpulan halaman-halaman yang digunakan untuk menapilkan informasi teks, gambar diam ataupun gerak, animasi, suara, dan atau gabungan dari semuahnya baik yang bersifat statis maupun dinamis yang membentuk suatu rangkaian yang saling terkait, yang masing-masing hubungan di kaitkan dengan jaringan-jaringan halaman.

Menurut Abdulloh(2018) dapat diartikan sebagai proses atau cara membuat program mengunakan bahasa pemograman tertentu sehingga dapat memproses data dan menghasilkan informasi sesuai yang di kehendaki.

Menurut Lubis(2016) Basis Data merupakan gabungan file yang dibentuk dengan hubungan/relasi yang logis dan dapat diuangkapkan dengan catatan serta bersifat independen. Adapun basis data adalah Tempat berkumpulnya data yang saling berhubungan dalam suatu wadah (organisasi/perusahaan) bertujuan agar dapat mempermudah dan mepercepat untuk pemanggilan atau memanfaatkan kembali data tersebut.

Menurut Putratama,virdiandry (2018) PHP atau (Hypertext Preprocessor) adalah suatu bahasa pemograman yang digunakan untuk menerjemahkan baris kode program menjadi kode mesin yang dapat dimengerti oleh computer yang bersifat server-side yang dapat ditambahkan kedalam HTML.

Menurut (Hikmah, 2015) PhpMyadmin merupakan aplikasi yang dapat digunakan untuk membuat database, penggunaan (user), memodifikasi table, maupun mengirim database secara cepat dan mudah tanpaharus menggunakan perintah (command) SQL.

Menurut Radillah (2018) MySQL adalah 
sebuah program database server yang mampu menerima dan mengirm datanya dengan sangat cepat, multi user serta menggunakan perintah standar SQL (Structure Quered Language).

Menurut Dermawan \& Hartini, (2017) Waterfall adalah model SDLC air terjun (waterfall) sering juga disebutmodel sekuensial linier (sequential llinear) atau alur hidup klasik (classic life cycle). Model air terjun menyediakan pendekatan alur hidup perangkat lunak secara sekuensial atau terurut dimulai dari analisis, desain, pengodean, pengujian dan tahap pendukung (support).

Menurut Hidayatulloh, (2015) Entity Relationship Diagram (ERD) merupakan teknik yang digunakan untuk memodelkan kebutuhan data dari suatu organisasi, biasanya oleh System Analys dalam tahap analisis persyaratan proyek pengembangan system. Sementara seolah-olah teknik diagram atau alat peraga memberikan dasar untuk desain database relasional yang mendasari sistem informasi yang dikembangkan.

Menurut (Mahdiat dkk, 2016) Logical Record Structured (LRS) adalah representasi dari struktur record-record pada tabel-tabel yang terbentuk dari hasil relasi antar himpunan entitas. Menentukan kardinalitas, jumlah tabel, dan ForeignKey (FK). Berikut adalah cara membentuk skema database atau LRS (Logical Record Strutured).

Menurut Herliana \& Rasyid, (2016)

UML adalah 'bahasa' pemodelan untuk sistem atau perangkat lunak yang perpradigma 'berorientasi' objek. Pemodelan sesungguhnya digunakan untuk penyederhanaan permasalahanpermasalahan yang kompleks sedemikian rupa sehingga lebih mudah dipelajarin dan di pahami. Beberapa literature menyebutkan bahwa UML menyediakan sembilan jenis diagram, yang lain menyebutkan delapan karena ada beberapa diagram yang digabung, misalnya diagram komunikasi, diagram urutan dan diagram pewaktuan digabung menjadi diagram interkasi.

\section{Metode Penelitian}

Teknik pengumpulan data yang digunakan oleh penulis dalam melakukan pengumpulan data :
1. Observasi

Pengamatan langsung di PT Asia Truk Pratama dan praktek terhadap objek alat yang akan dibuat oleh penulis serta proses kerja alat yang akan dibuat oleh penulis pada PT Asia Truk Pratama di bagian penjualan.

2. Wawancara

Dalam metode wawancara ini, penulis dapat memperoleh data informasi langsung dari bapak Feriardi Prasonggo bagian penjualan dengan cara melakukan tanya jawab dan bertatap muka antar penulis dengan narasumber.

3. Studi Pustaka

Sebagai pendukung dalam mencari berbagai informasi berupa teoriteori, sebagai buku refrensi yang berkaitan dengan judul tugas akhir. Penulis mengambil beberapa materi dari beberapa web dan jurnal.

Dimulai dari saat customer mengisi form pembelian barang untuk membeli suku cadang PT Asia Truk Pratama yang kemudian dipersiapkan oleh bagian operasional, lembar pertama untuk customer lembar kedua untuk admin setelah itu bagian operasional meberi tau rincian pembayaran. Lalu customer melakukan pembayaran setelah melakukan pembayaran bagian operasional memberikan kwitansi dan bukti pembelian sebagai bukti pembayaran dan pembelian yang sah dan yang telah ditanda tangani. Setelah melakukan pembayaran dan menerima kwitansi pembayaran maka penyewa baru dapat membawa suku cadang yang dibeli. Apabila customer ingin barangnya di anatar maka customer harus menyerahakan bukti pembelian dan kwitansi pembayaran .

Apabila ada suku cadang yang salah ukuran atau tidak sesuai dengan spesifikasi customer harus menunjukan bukti pembelian dan kwitansi kepada opersional lalu akan di cek Setelah itu barulah dibuat laporan keuangan setiap bulannya untuk di serahkan ke direktur. 


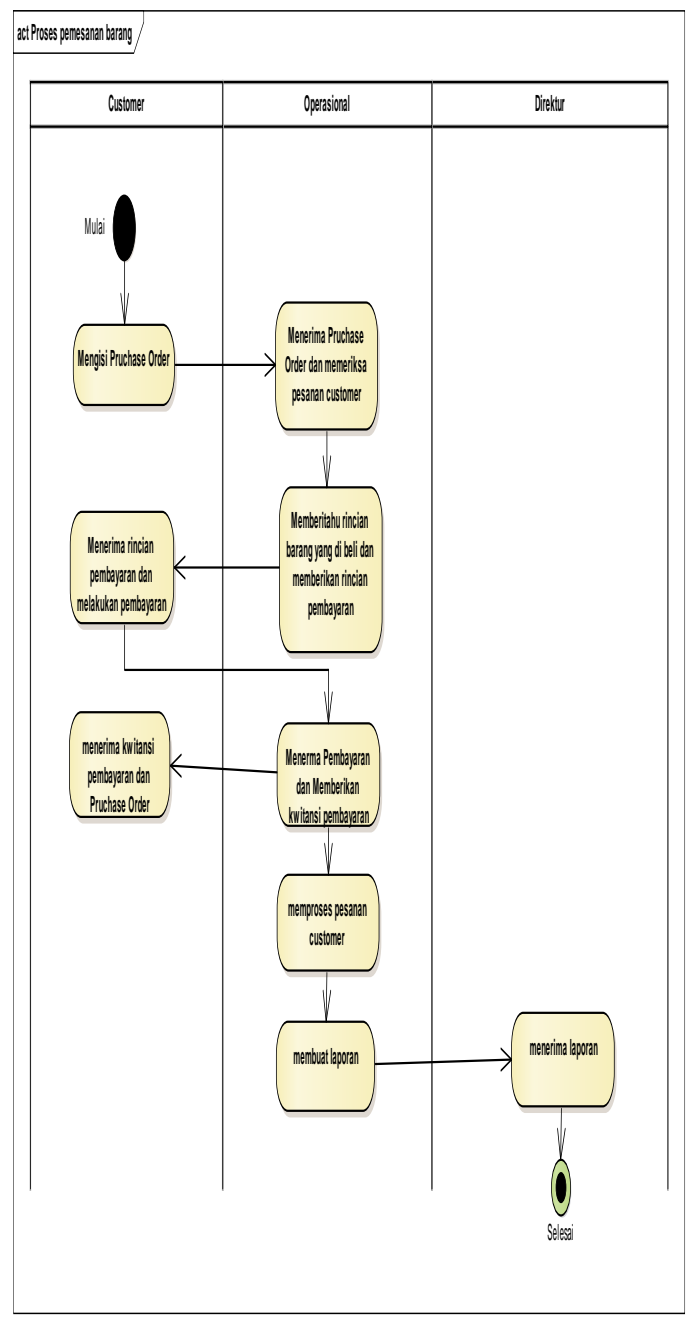

Sumber : hasil penelitian (2019)

Gambar 1 Activiy Diagram Sistem Berjalan

Berdasarkan analisis sistem berjalan pada sekolah, penulis dapat mengusulkan beberapa masalah yang ada, yaitu:

1. Proses jual beli masih menggunakan sistem manual.

2. Proses pembelian hanya bias dilakukan pada saat perusahaan buka.

3. Cara memesan barang menjadi kurang efektif karna pada saat datang keperusahaan tersebut belum tentu barang yang diinginkan tersedia.

4. Laporan penjualan dan laporan stok barang masih menggunakan sistem manual.

Berdasarkan permasalahan pokok yang ada penulis megusulkan beberapa pemecahan masalah, yaitu :

1. Membuat perancangan sistem penjualan untuk mempermudah customer dalam melakukan pembelian barang.
2. Dalam proses sistem informasi penjualan barang memberikan kemudahan dalam membeli barang dimana saja dan kapan saja.

3. Dalam proses sistem informasi untuk operasional memberikan kemudahan dalam mengontrol penjualan.

4. Proses pembuatan laporan setelah adanya perancangan sistem informasi penjualan menjadi lebih efesien dan efektif.

\section{Hasil dan Pembahasan}

Use case usulan

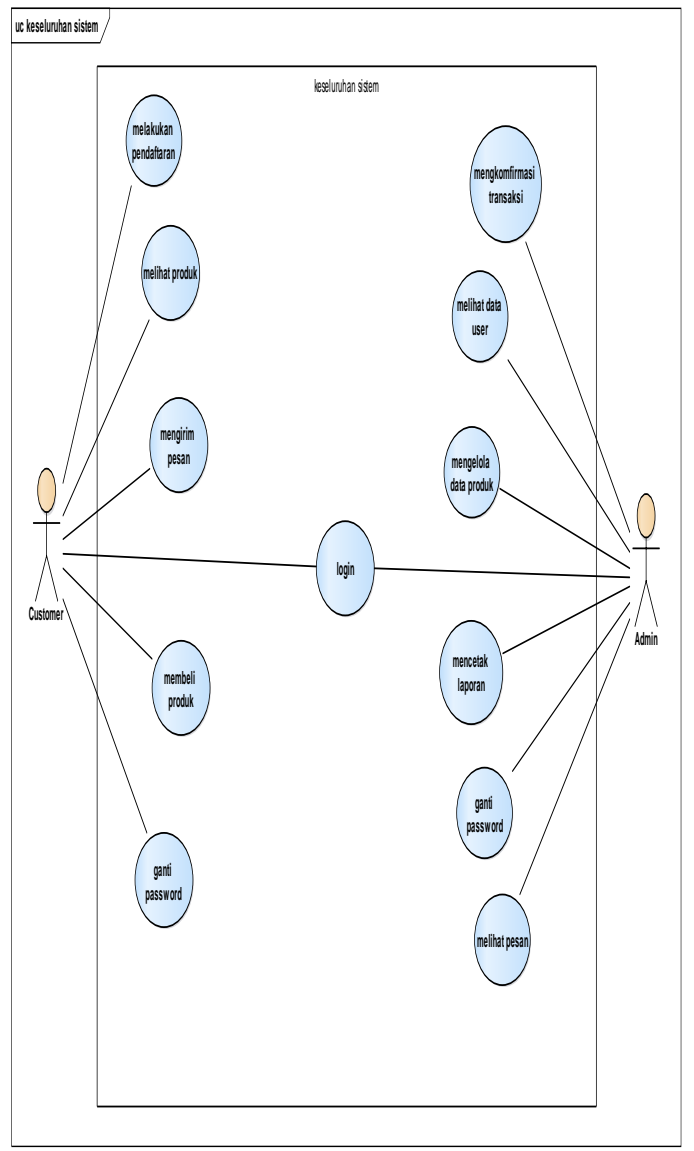

Gambar 2 Use Case

Tabel 1

Deskripsi Use Case Lihat Produk

\begin{tabular}{|l|l|}
\hline Use Case Name & Melihat produk \\
\hline Requirement & - \\
\hline Goal & Melihat produk \\
\hline Pre-Condition & Masuk halaman web \\
\hline Post-Condition & - \\
\hline Failed end Condition & - \\
\hline Actors & Pembeli \\
\hline Main Flow / Basic Path & 1. Masuk kehalaman \\
& 2. Web Klik menu produk \\
& 3. Klik kategori yang \\
& \\
& \\
&
\end{tabular}




\begin{tabular}{|l|l|}
\hline & $4 . \quad \begin{array}{l}\text { Pilih produk yang } \\
\text { di inginkan }\end{array}$ \\
\hline $\begin{array}{l}\text { Alternate Flow / } \\
\text { Invariant } A\end{array}$ & - \\
\hline Invariant B & $\begin{array}{l}\text { B1. Masuk kehalaman } \\
\text { web } \\
\text { B2. Klik menu produk } \\
\text { B3. Klik kategori yang di } \\
\text { inginkan } \\
\text { B4.Sistem menampilkan } \\
\text { produk yang dicari }\end{array}$ \\
\hline
\end{tabular}

Tabel 2

Deskripsi Use Case Login

\begin{tabular}{|c|c|}
\hline $\begin{array}{ll}\text { Use } & \text { Case } \\
\text { Name } & \end{array}$ & Login \\
\hline Requirement & - \\
\hline Goal & Masuk kehalaman member \\
\hline Pre-Condition & $\begin{array}{l}\text { Pembeli mengunjungi halaman } \\
\text { login }\end{array}$ \\
\hline $\begin{array}{l}\text { Post- } \\
\text { Condition }\end{array}$ & Pembeli harus sudah terdaftar \\
\hline $\begin{array}{l}\text { Failed end } \\
\text { Condition }\end{array}$ & $\begin{array}{l}\text { Kalau username dan password } \\
\text { salah pembeli akan } \\
\text { dikembalikan kehalaman login }\end{array}$ \\
\hline Actors & Pembeli \\
\hline $\begin{array}{l}\text { Main Flow / } \\
\text { Basic Path }\end{array}$ & $\begin{array}{ll}\text { 1. } & \text { Pembeli mengunjungi } \\
\text { halaman login } \\
\text { 2. Pembeli mengisi form login } \\
\text { 3. Klik tombol login } \\
\text { 4. Sistem mengalihkan } \\
\text { pembeli kehalaman } \\
\text { member }\end{array}$ \\
\hline $\begin{array}{l}\text { Alternate } \\
\text { Flow } \\
\text { Invariant A }\end{array}$ & $\begin{array}{l}\text { A1. Sistem menampilkan } \\
\text { pemberitahuan username } \\
\text { atau password salah. }\end{array}$ \\
\hline Invariant $B$ & $\begin{array}{l}\text { B1.Pembeli mengunjungi } \\
\text { halaman login } \\
\text { B2. Pembeli mengisi form login } \\
\text { B3. Klik tombol login } \\
\text { B4. Sistem mengalihkan } \\
\begin{array}{l}\text { pembeli malaman } \\
\text { member. }\end{array}\end{array}$ \\
\hline
\end{tabular}

Tabel 3

Deskripsi Use Case Berbelanja

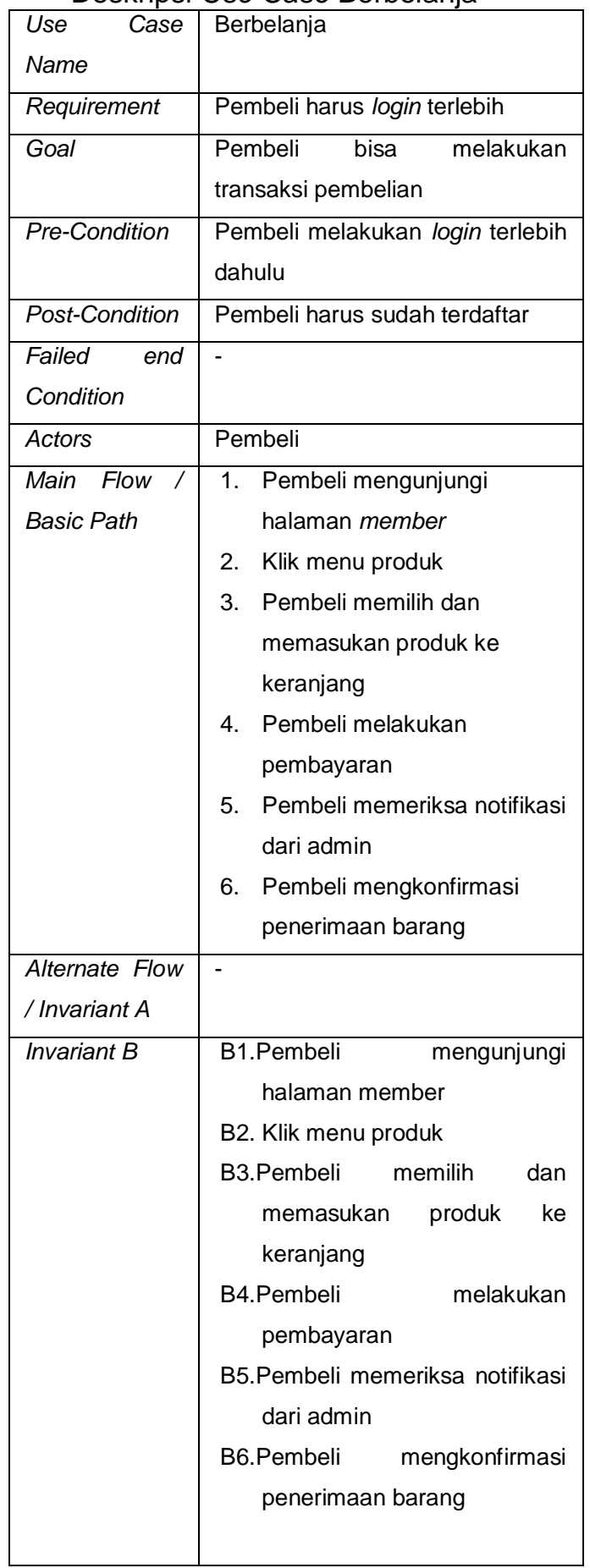


Activity Diagram Pembelian

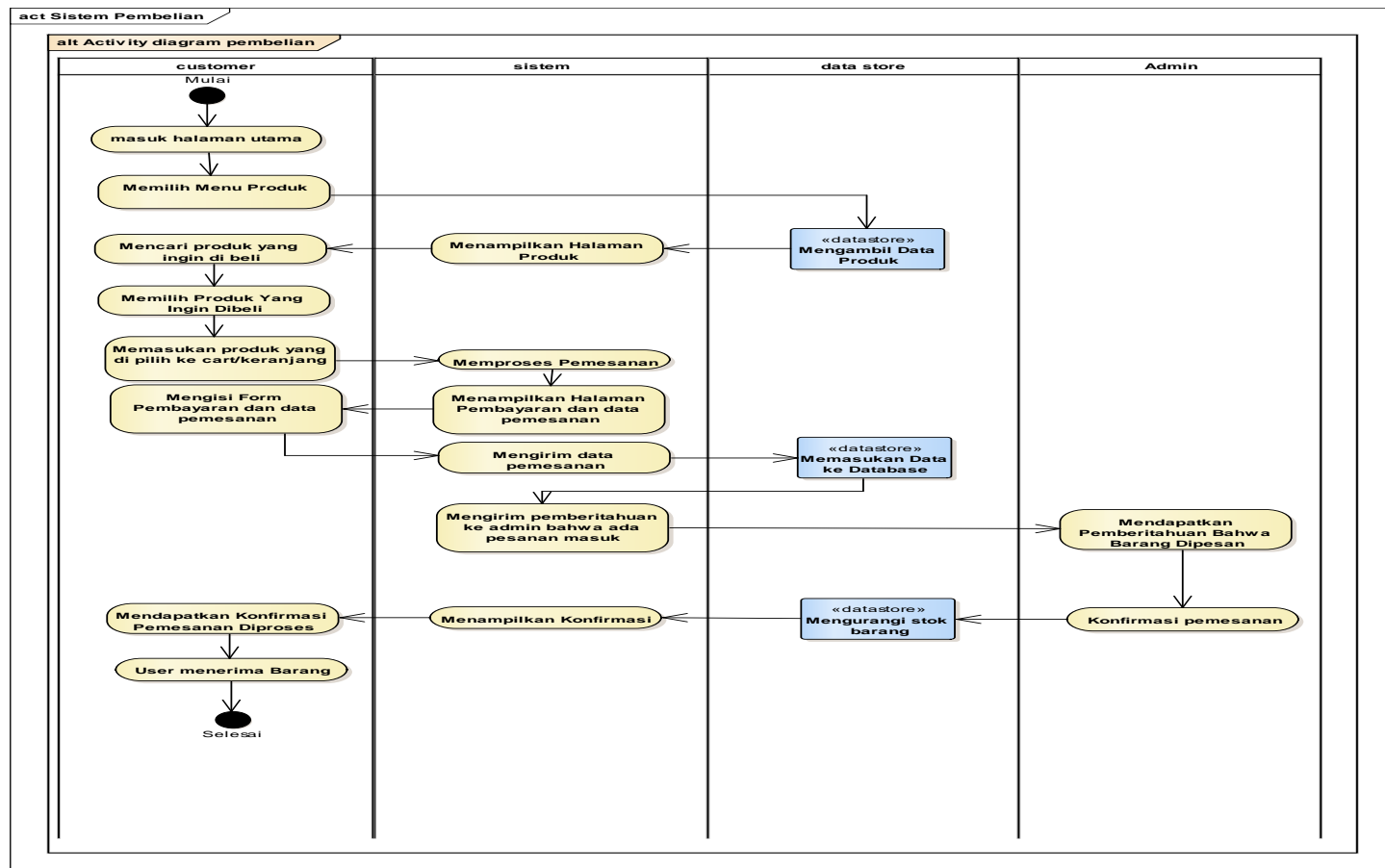

Gambar 3 Diagram Activity Pembelian

Rancangan Halaman Depan

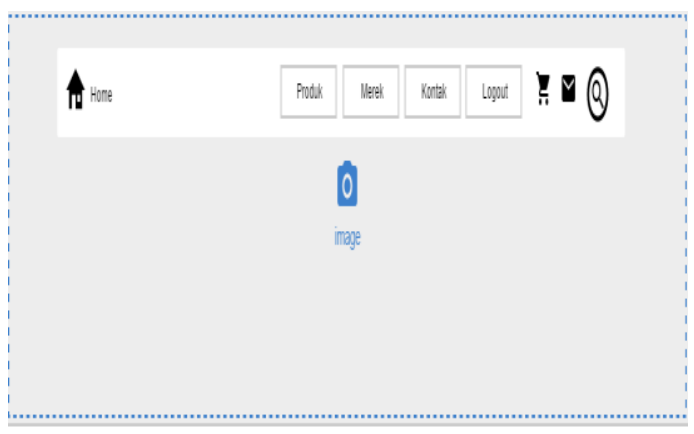

Content

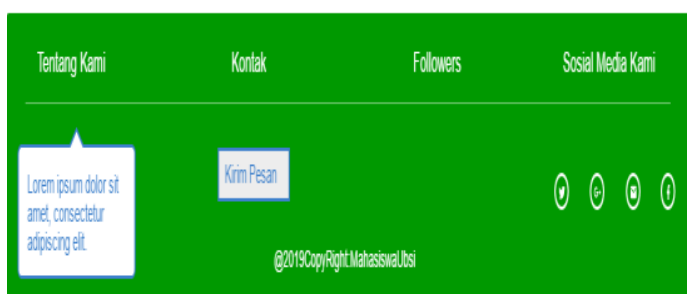

Gambar 4. Halaman Depan
Rancangan Home Member

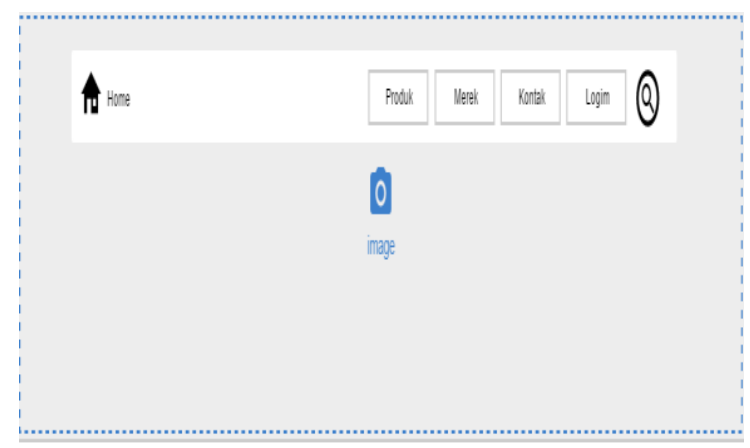

Content:

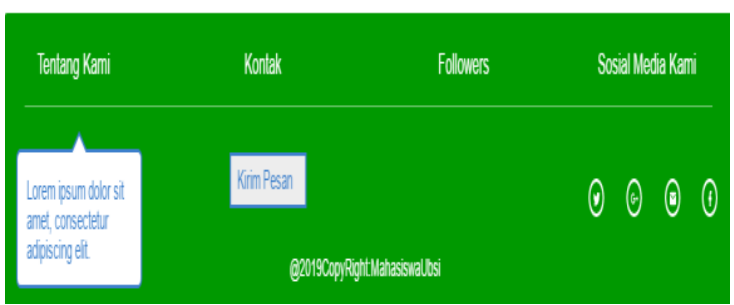

Gambar 5. Home Member 
Rancangan Home Admin

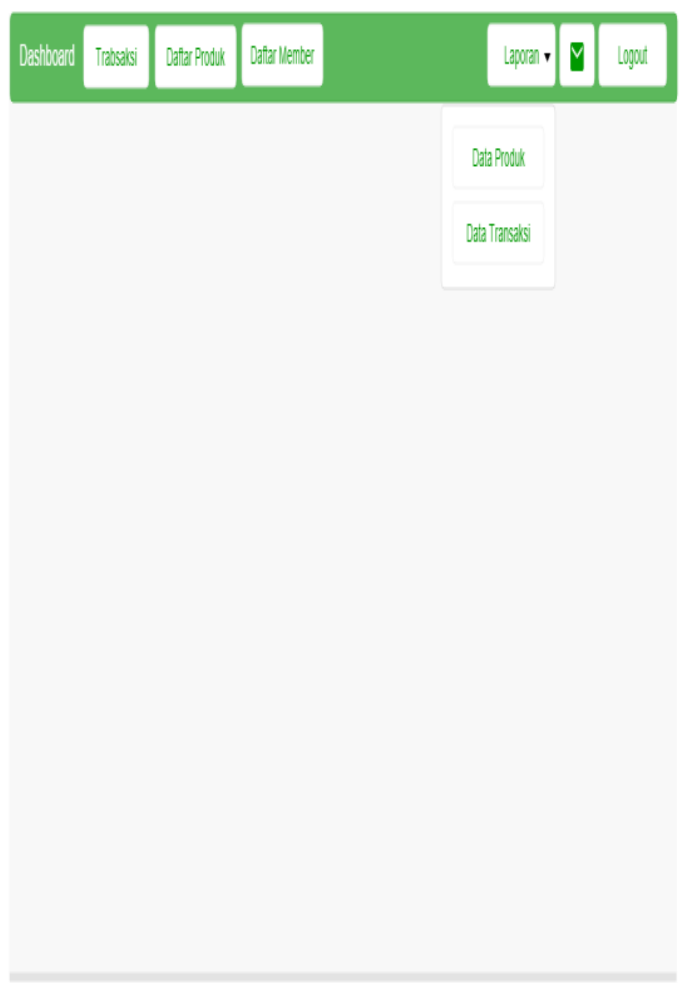

Gambar 6. Rancangan Home Admin

\section{Kesimpulan}

Dari penelitian tentang perancangan sistem informasi penjualan barang berbasis web pada PT Asia Truk Pratama, maka penulis dapat menarik kesimpulan sebagai berikut :

1. Dengan sistem informasi penjualan barang berbasis web pada PT Asia Truk Pratama, yang sudah terkomputerisasi ini dapat membantu mengurangi kesalahan yang terjadi pada sistem yang masih di gunakan oleh PT Asia Truk Pratama,.

2. Sistem informasi pelayanan penjualan ini dapat memudahkan dalam proses penjualan suku cadang truk karena setiap prosesnya terintegrasi satu sama lain.

3. Tingkat keamanan data lebih terjaga karena disimpan ke dalam suatu database yang terkomputerisasi.

4. Perancangan sistem informasi pengolahan nilai berbasis web pada PT Asia Truk Pratama, ini dapat mempermudah dalam hal pembuatan laporan serta mempermudah dalam hal pencarian data.

\section{Referensi}

Abdulloh, R. (2018). 7 in 1 Pemrograman Web untuk Pemula. Retrieved from https://books.google.co.id/books?id $=21 \mathrm{FwDwAAQBAJ} \& p g=P A 2 \& d q=d$ apat+diartikan+sebagai+proses+at au+cara+membuat+program+meng gunakan+bahasa+pemograman+ter tentu+sehingga+dapat+memproses +data+dan+menghasilkan+informa si+sesuai+yang+di+kehendaki\&hl=i $\mathrm{d} \& \mathrm{sa}=\mathrm{X} \& \mathrm{ved}=0 \mathrm{ah}$

Batubara, H. H. (2018). Pembelajaran Berbasis Web Dengan Moodle Versi 3.4 (1st ed.). sleman: deepulish.

Dermawan, J., \& Hartini, S. (2017). "Implementasi model waterfall pada pengembangan berbasis web pada sekolah dasar al-azhar syifa budi jatibening." 19(2).ntasi model waterfall pada pengembangan berbasis web pada sekolah dasar al-azhar syif. 19(2).

Herliana, A., \& Rasyid, P. M. (2016). Sistem informasi monitoring pengembangan software pada tahap.

Hermawan, H. \& ir. yuniar supardi. (2018). Books on Google Play Semua Bisa Menjadi Programmer Codelgniter Basic. Elex Media Komputindo.

Hidayatulloh, T. (2015). Perancangan sistem penjadwalan pembelajaran menggunakan graph coloring. II(2), 416-424.

Hikmah, A. B. (2015). Cara Cepat Membangun Website dari Nol (1st ed.). Retrieved from https://books.google.co.id/books?id $=$ P7d4CwAAQBAJ\&printsec $=$ frontc over\&dq=Cara+Cepat+Membangun + Website+dari+Nol\&hl=id\&sa $=X \& v$ ed=0ahUKEwi4sP3ZrMLjAhXzmeY KHb6qBowQ6AEIKDAA\#v=onepag $\mathrm{e} \& \mathrm{q}=$ Cara Cepat Membangun Website dari Nol\&f=false

Hutahean, J. (2015). konsep sistem informasi (1st ed.). sleman: Deepublish. 
Lubis, A. (2016). Basis Data Dasar (1st ed.). Yogyakarta: DEEPUBLISH.

Mahdiati, Thias; Fridayanti, W. E. (2016). rancangan bangun sistem informasi permintaan atk berbasis intranet. IV(2), 126-138.

Marisa, F. (2017). Web Programming (Client Side and Server Side (1st ed.). sleman: DEEPUBLISH.

Mulyani, S. (2016). Metode Analisis dan Perancangan Sistem (2nd ed.). Bandung: Abdi Sitematika.

Putratama, virdiandry, S. (2018). Pemrograman Web dengan Menggunakan PHP dan Framework Codeigniter (1st ed.). Yogyakarta: DEEPUBLISH.
Radillah, T. (2018). VB 6.0 Return (1st ed.). Retrieved from https://books.google.co.id/books?id $=r m 9 n D w A A Q B A J \& p g=P A 14 \& d q=$ pengertian+mysql\&hl=id\&sa $=X \& v e$ $\mathrm{d}=0$ ahUKEwjAwfOdssLjAhXq6nMB HX7iAtMQ6AEILzAB\#v=onepage\& $q=$ pengertian mysq $\& f=$ false

Rusmawan, U. (2019). Teknik Penulisan Tugas Akhir dan Skripsi Pemrograman. Jakarta: PT Elex Media Komputindo.

Wahyuni, I. H. (2018). Kebijakan Media Baru Di Indonesia (2nd ed.). Yogyakarta: Gadjah mada university press. 